This item was submitted to Loughborough's Research Repository by the author.

Items in Figshare are protected by copyright, with all rights reserved, unless otherwise indicated.

\title{
Training-related and competition-related risk factors for respiratory tract and gastrointestinal infections in elite cross-country skiers
}

PLEASE CITE THE PUBLISHED VERSION

http://dx.doi.org/10.1136/bjsports-2015-095398

\section{PUBLISHER}

BMJ Publishing Group / @ The Authors

VERSION

AM (Accepted Manuscript)

\section{PUBLISHER STATEMENT}

This work is made available according to the conditions of the Creative Commons Attribution-NonCommercialNoDerivatives 4.0 International (CC BY-NC-ND 4.0) licence. Full details of this licence are available at: https://creativecommons.org/licenses/by-nc-nd/4.0/

\section{LICENCE}

CC BY-NC 4.0

\section{REPOSITORY RECORD}

Svendsen, Ida, Ian Taylor, Espen Tonnessen, Roald Bahr, and Michael Gleeson. 2016. "Training-related and Competition-related Risk Factors for Respiratory Tract and Gastrointestinal Infections in Elite Cross-country Skiers". Loughborough University. https://hdl.handle.net/2134/20677. 


\title{
Training- and competition-related risk factors for respiratory tract and gastrointestinal infections in elite cross-country skiers
}

\author{
Ida S. Svendsen ${ }^{1}$, Ian M. Taylor ${ }^{1}$, Espen Tønnessen ${ }^{2}$, Roald Bahr ${ }^{2,3}$, Michael Gleeson ${ }^{1}$
}

1) School of Sport, Exercise and Health Sciences, Loughborough University, Loughborough, UK.

2) Department of Training, Norwegian Olympic and Paralympic Committee and Confederation of Sports, Oslo, Norway.

3) Oslo Sports Trauma Research Center, Department of Sports Medicine, Norwegian School of Sport Sciences, Oslo, Norway.

\section{Address for Correspondence:}

Ida Siobhan Svendsen

School of Sport, Exercise and Health Sciences,

Loughborough University,

Leicestershire, UK.

LE11 3TU.

E-mail: i.s.svendsen@lboro.ac.uk

Telephone: +447794904859

Manuscript word count: 3585

Key words: infection; risk factor; athletes; travel; altitude. 


\section{ABSTRACT}

Aim: To examine symptoms indicative of respiratory tract and gastrointestinal infection and determine risk factors for such symptoms in elite cross-country skiers.

Methods: Self-reported training and symptom data for 37 elite cross-country skiers from 2007-2015 were analysed using multilevel logistic regression equations with symptom incidence and duration as outcome variables, and sex, performance level, season, competition, air travel, altitude exposure, and training characteristics as independent variables.

Results: Data for 7,016 person-weeks were analysed, including 464 self-reported infection events and 110,959 hours of training. Athletes reported median (range): 3 (1-7) respiratory tract and/or gastrointestinal events per year, with symptoms lasting 5 (1-24) days. During the winter, symptoms occurred more frequently (odds ratio $2.09, P<0.001$ ) and lasted longer ( $b=0.043, P<0.001)$ compared to summer. Competition and air travel increased the risk of symptoms, with odds ratios of 2.93 (95\% CI: 2.24-3.83) and 4.94 (95\% CI: 3.74-6.53), respectively $(P<0.001)$. Athletes with higher Training Monotony had lower risk of symptoms (odds ratio 0.87 (95\% CI: 0.73-0.99), $P<0.05$ ). Other training variables were not associated with symptoms. Athletes who had won an Olympic/World Championship medal reported shorter symptom duration compared to less successful athletes $(b=-0.019, P<0.05)$ resulting in significantly fewer symptomatic days per year (14 (6-29) vs. 22 (8-43) days/year).

Conclusions: Air travel and competition are major risk factors for acute respiratory tract and gastrointestinal symptoms in this population. Athletes who have large fluctuations in training load experience such symptoms more frequently. Shorter duration of symptoms appears to be associated with success in cross-country skiing.

\section{INTRODUCTION}


Reaching an international level in any sport requires a high volume of training, and elite endurance athletes typically train between $500 \mathrm{~h}^{12}$ to in excess of $1,000 \mathrm{~h}$ per year ${ }^{3-5}$, with elite cross-country skiers training $\sim 800 \mathrm{~h}_{\text {per year }}{ }^{6}$. In the general population, adults typically experience two to four respiratory tract infections per year ${ }^{78}$. However, crosssectional studies indicate that individuals with high training loads experience a greater frequency of upper-respiratory tract infections ${ }^{9}$. Furthermore, longitudinal studies with athletes report an increased infection incidence during periods of intense training or competition ${ }^{10-11}$. Malm ${ }^{12}$ suggested that, although high training loads may suppress immunity, becoming a successful elite athlete requires an immune system capable of withstanding infections even during severe physiological and psychological stress. However, differences in infection susceptibility between the most successful athletes and their less successful counterparts, all of whom have similarly high training loads, has not been fully explored. It is possible that the ability to withstand and/or recover quickly from an infection, particularly during key training and competition periods, could be a predictor of success within an otherwise homogenous athlete group.

A recent study by Hellard et al. ${ }^{11}$ investigated infection incidence amongst international swimmers over a four-year period, and found that infection rates were highest during the winter months and intensive training periods. However, it is not clear whether the same patterns for infection incidence are present for winter sports athletes, who compete during the winter months but typically undertake the highest training loads in the summer and autumn ${ }^{6}$. Furthermore, other than high training loads, elite athletes are exposed to a number of additional stressors, such as frequent international travel, altitude exposure and the psychological pressure of competition, which may also influence infection susceptibility ${ }^{13-15}$. The primary purpose of the study was to examine the incidence of symptoms indicative of respiratory tract and gastrointestinal infection in elite cross-country skiers and to determine 
risk factors for such infections in this population. A secondary aim was to examine possible differences in the frequency and/or duration of symptoms between athletes that have won an Olympic/World Championship medal, and those athletes that have not. It was hypothesised that heavy training loads and competition would significantly increase the risk of symptoms, and that athletes who had medalled at world or Olympic level would report fewer illness events.

\section{METHODS}

\section{Participants}

This retrospective cohort study was based on self-reported training and symptom data from 39 elite male $(n=22)$ and female $(n=17)$ cross-country skiers for the period 01.05.2007 to 30.03.2015. Athletes on the Norwegian national team are required to log their training data daily as a condition for receiving an annual stipend. Athletes were recruited via convenience sampling using the following inclusion criteria: 1) selected to represent the Norwegian national senior or recruit team for cross-country skiing during the analysed time period, 2) over 18 years of age, and 3) having recorded their day-to-day training from junior through to senior level in detail. As of 30.03.2015, 16 of these athletes ( 9 males and 7 females) had won at least one individual senior Olympic or World Championship medal (totalling 73 individual Olympic and World Championship medals between them). These athletes were categorised as world-leading (WL), while those athletes that had not won an individual Olympic or World Championship medal were categorised as international level (IL). All athletes provided written, informed consent for their data to be included in the study, which was approved by the Loughborough University Ethical Review Committee and registered with the Norwegian Data Protection Authority.

\section{Definition of symptoms}


Athletes recorded training and symptoms in spreadsheet training diaries designed by the Norwegian Ski Federation or, since 2012, in the web-based version developed by the Norwegian Olympic Federation (www.olt-dagbok.net). Each day included a "parametrics" and a "free text" field where athletes recorded symptoms and whether training was discontinued or modified due to illness or injury, acute medication use, days of travel and days spent at altitude. Based on the definitions proposed by Matthews et al. ${ }^{16}$ an infection event was defined as an athlete reporting one or more symptoms indicative of respiratory or gastrointestinal infection on two or more consecutive days, or when symptoms were severe enough that training was completely discontinued on at least one day. Symptoms had to be separated by a minimum of seven days in order to be categorised as two separate events. Only symptoms likely due to respiratory tract or gastrointestinal infection were retained for analyses. These included upper respiratory tract symptoms (blocked or runny nose, sore throat, sneezing), lower respiratory tract symptoms (coughing, sputum, chest congestion, wheezing, fever) and gastrointestinal symptoms (nausea, vomiting, diarrhoea, abdominal pain). Each event was categorised as either symptoms indicative of respiratory tract infection (RTI) or symptoms indicative of gastrointestinal infection (GII). The number of days of symptoms of each event was recorded.

\section{Categorization of training}

The training recorded for each session included total training time for different training forms (endurance, strength/power, sprint, etc.) and intensity zone (Table 1). Rolling one, three and seven day averages for total training volume, the volume of high-intensity training and the volume of strength/power/sprint training were calculated. Training impulse ${ }^{17}$ (TRIMP $=$ training duration (min) x intensity (HR zone 1-5), Training Monotony (mean TRIMP / SD TRIMP) and Training Stress (TRIMP x training monotony) scores ${ }^{18}$ were also calculated. In addition, the number of competitions, number of international flights and number of days at 
altitude $(\geq 1,500$ metres above sea level (masl)) during the previous one, three, and seven days were calculated.

Table 1. The 5-zone intensity scale used by athletes to classify endurance training

\begin{tabular}{cccc}
\hline $\begin{array}{c}\text { Intensity } \\
\text { Zone }\end{array}$ & $\begin{array}{c}\text { Typical Blood } \\
\text { Lactate } \\
(\mathbf{m m o l} / \mathbf{L})\end{array}$ & $\begin{array}{c}\text { Typical } \\
\text { Heart Rate } \\
(\boldsymbol{\%} \text { max })\end{array}$ & Binary Model \\
\hline 5 & $>5.8$ & $>94$ & \\
4 & $3.7-5.7$ & $89-93$ & HIT \\
3 & $2.1-3.6$ & $84-88$ & \\
\hline 2 & $1.3-2.0$ & $74-83$ & LIT \\
1 & $<1.2$ & $54-73$ & \\
\hline
\end{tabular}

Reference values presented are derived from the average self-reported zone cut-offs of 29 elite XC-skiers ${ }^{6}$.

\section{Statistical analysis}

To explore which factors were associated with onset of symptoms, multilevel modelling was employed using MLwiN software (version 2.32; University of Bristol). Multilevel logistic regression equations were constructed to predict symptom incidence, which was treated as a binary ( $0=$ did not report symptoms, $1=$ did report symptoms) outcome variable. Firstly, we explored whether symptoms occurred more frequently for males compared with females $(0=$ males, $1=$ female $)$, for athletes of different performance levels $(0=\mathrm{IL}, 1=\mathrm{WL})$, during different times of year (spring (March-May), summer (June-August), autumn (SeptemberNovember) and winter (December-February)) and during different training phases (transition phase, general preparation phase, specific preparation phase, competition phase, regeneration phase) by including these as categorical independent variables in separate multilevel models. Training variables, air travel, altitude exposure and competition were entered into separate models as independent variables to determine unadjusted odds ratios. In order to disaggregate within-person and between-person associations, each participant's aggregate for each variable 
was centred on the grand mean and entered into the level 2 equation to determine whether an individual with higher average values for that independent variable had a higher incidence of symptomatic episodes, compared to an individual with lower average values (between-person relationships). Each variable was also centred on each participant's unique mean and entered into the level 1 equation to determine whether fluctuations around an individual's average were associated with changes in symptom incidence (within-person relationships). Odds ratios for training variables represent the increase in risk of symptoms occurring as a result of a $1 \mathrm{~h} /$ week increase in that training variable, or a 10\% increase in Training Monotony, Training Stress and TRIMP. Based on the unadjusted models described above, adjusted logistic multilevel models were constructed with all significant independent variables from the unadjusted models included. Multilevel regression equations were also constructed to determine whether sex, performance level, type of symptoms (RTI or GII), season, training phase or training load during illness were significantly associated with duration of symptoms. Results are reported as the median with range, unless otherwise stated. Significance was accepted at the $P<0.05$ level.

\section{RESULTS}

In total, from 39 athletes, 7,436 person weeks of data were collected. Of these, two athletes (316 person-weeks) were excluded due to inadequate detail in the recording of symptoms. For two athletes, one season was excluded per athlete due to confirmed cases of mononucleosis, while data for previous and/or subsequent seasons were retained. 7,016 person-weeks were therefore included in the final analysis. These included 464 events of GII and RTI, 110,959 h of training, 3,812 competitions, 1,769 international flights and 4,879 days at altitude $>1,500$ masl. Of all the training recorded, $91 \%$ was endurance training and $9 \%$ was 
strength/power/sprint training (Table 2). Of endurance training, 90\% was at low intensity (Izone 1 and 2), and 10\% was at high intensity (I-zone 3-5).

\section{Symptom incidence}

All of the athletes reported at least one episode of RTI or GII during the analysed time period. However, there was considerable inter-individual variation in the number and duration of symptomatic episodes, with athletes reporting 3.4 (0.6-6.8) events and 19 (6-43) days of symptoms per year. Of these, 410 events were RTI, equivalent to 3.0 events per athlete per year, and 54 events were GII, equivalent to 0.4 events per athlete per year. Sixteen percent of athletes experienced $\geqslant 6$ events per year and were hence categorized as "illness prone". The average duration of symptoms was 5 (1-24)days, with this being significantly longer for RTI compared to GII ( $5 \pm 4$ vs. $3 \pm 2$ days, $b=-1.294, P<0.001)$.

\section{Risk factors for RTI and GII}

Unadjusted and adjusted odds ratios for all the candidate risk factors are presented in Tables 3 and 4. Analysing respiratory tract symptoms separately from gastrointestinal symptoms did not affect which variables were associated with onset of symptoms.

Sex, performance level and family situation

Sex was not a significant risk factor for either symptom incidence or symptom duration, and neither was living in a household with young children However, performance level was significantly associated with the duration of symptoms, with this being lower for WL athletes $(b=-0.019, P=0.034)$. Consequently, WL athletes reported a lower total number of symptomatic days per year compared with IL athletes (14 (6-29) days/year vs. 22 (8-43) days/year), despite no significant between-group differences in training load, number of flights, competitions or days spent at altitude. 
Table 2: Training variables and symptom incidence by sex, performance level, training phase and season during 7,016 person-weeks for 37 elite cross-country skiers.

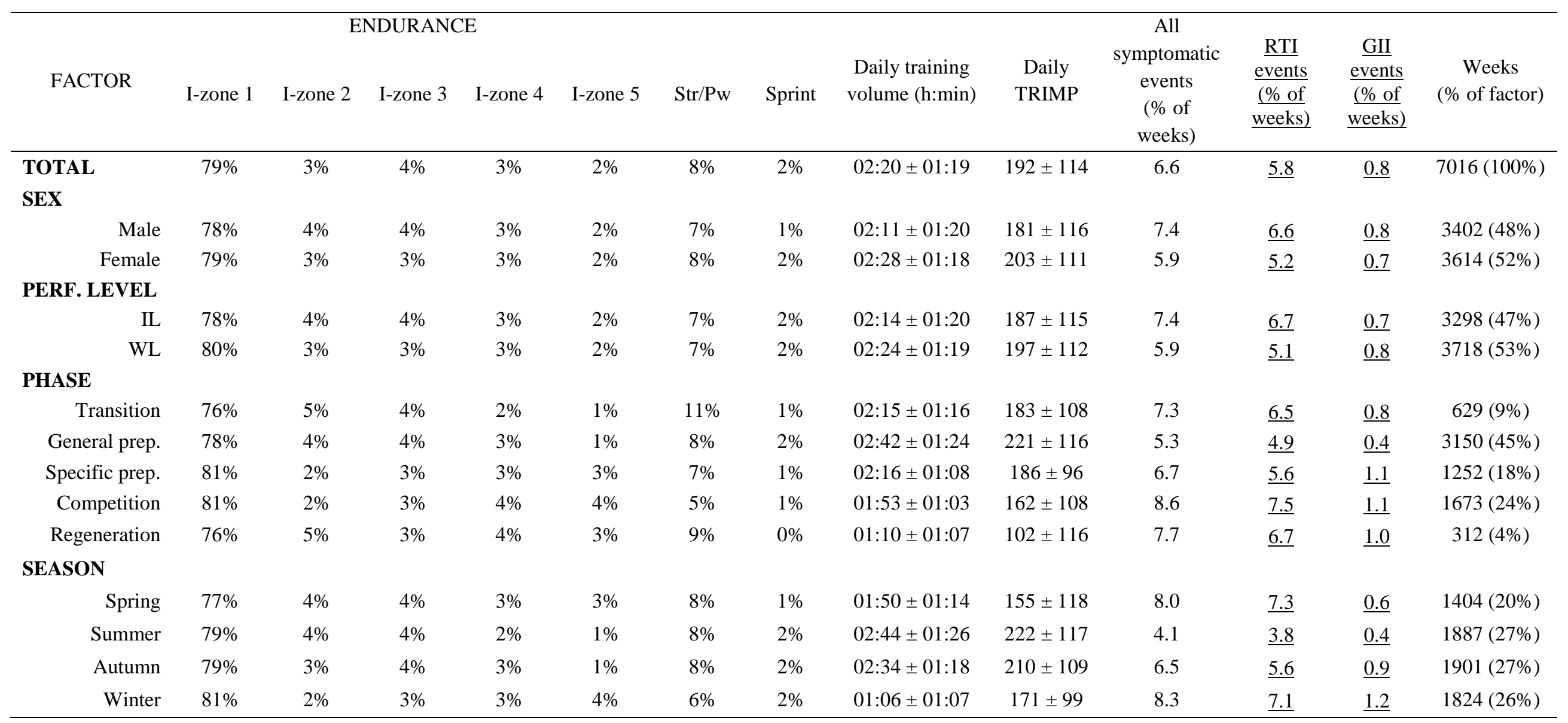

1 For endurance training in each of the five intensity zones, strength/power ( $\mathrm{Str} / \mathrm{Pw})$ and sprint training values are percentages of total training

2 volume. Daily training volume and daily Training Impulse (TRIMP) are presented as mean \pm SD. IL: International level athletes; WL: World-

3 leading athletes (minimum one individual senior Olympic/World Championship medal) 
Predictor variable

Estimated odds ratio $(95 \% \mathrm{CI})$

Within subject

Between subject

$\operatorname{Sex}(\mathrm{M}=0)$ $0.78(0.60-1.02)$

Age

$1.01(0.95-1.07)$

$1.02(0.99-1.05)$

Team (Recruit=0)

$0.87(0.68-1.11)$

Performance level $(\mathrm{IL}=0)$

$0.83(0.63-1.10)$

Family situation (No children $=0$ )

$0.98(0.67-1.44)$

Summer

1.00

Autumn

$1.63(1.23-2.16) *$

Winter

$2.09(1.59-2.73) *$

Spring

$2.00(1.50-2.65) *$

General Preparation Phase

1.00

Specific Preparation Phase

$1.28(0.99-1.65)$

Competition Phase

$1.68(1.35-2.09) *$

Regeneration Phase

1.56 (1.02-2.37)\#

Transition Phase

1.40 (1.01-1.92)\#

International air travel

$4.53(3.49-5.88) *$

$1.23(0.19-7.91)$

Altitude exposure

1.05 (1.01-1.10)\#

$0.81(0.52-1.27)$

Competition

$2.74(2.18-3.45) *$

$0.53(0.19-1.45)$

Total training volume

$0.98(0.97-1.00)$

$0.91(0.85-0.98) \#$

High-intensity endurance exercise

1.16 (1.03-1.31)\#

0.57 (0.30-1.09)

Strength/Power/Sprint exercise

$0.83(0.75-0.91) *$

$0.70(0.48-1.02)$

Training monotony

$1.01(0.99-1.02)$

$0.86(0.79-0.93) *$

Training impulse

$1.00(0.98-1.01)$

$1.06(1.00-1.12)$

Training stress

$1.00(1.00-1.00)$

0.97 (0.96-0.99)\#

Table 3: Unadjusted odds ratios for symptom onset for each predictor variable

Data for 7016 person-weeks from 37 elite cross-country skiers. 
* $P<0.001 ; \# P<0.05$

Table 4: Adjusted odds ratios for symptom onset for predictor variables retained in the final multilevel model

Predictor variable

Estimated odds ratio $(95 \% \mathrm{CI})$

Within subject Between subject

FIXED EFFECTS

Intercept

$-5.116^{*}$

PREDICTOR VARIABLES

Summer

1.00

Autumn

$1.65(1.20-2.25) *$

Winter

$1.91(1.11-3.27) *$

Spring

2.09 (1.09-3.99)*

General Preparation Phase

Specific Preparation Phase

$0.70(0.46-1.04)$

Competition Phase

$0.78(0.46-1.34)$

Regeneration Phase

$0.97(0.46-2.04)$

Transition Phase

$0.88(0.44-1.75)$

\section{International air travel}

$4.94(3.74-6.53) *$

$2.65(0.16-44.7)$

Altitude exposure

1.05 (1.00-1.10)

$0.76(0.38-1.53)$

Competition

$2.93(2.24-3.83) *$

$0.55(0.16-1.92)$

Total training volume

$1.01(0.98-1.04)$

$1.06(0.90-1.15)$

High-intensity endurance exercise

$1.08(0.95-1.24)$

$0.80(0.37-1.76)$

Strength/Power/Sprint exercise

$0.93(0.83-1.05)$

$0.82(0.51-1.33)$

Training monotony

$1.01(1.00-1.01)$

0.87 (0.73-1.00)\#

\section{RANDOM EFFECTS}

Intercept

0.066

$\mathrm{R}^{2}$

0.347

Data for 7016 person-weeks from 37 elite cross-country skiers. 
$* P<0.001 ; \# P<0.05$

Time of year

Athletes experienced significantly more symptomatic events during autumn, winter and spring compared with summer, with the highest probability of symptoms during the winter months (odds ratio (95\% CI): 2.09 (1.59-2.73), $P<0.001$ vs. summer). However, when adjusted for other independent variables, the highest risk of symptoms was in the spring (odds ratio (95\% CI): 2.09 (1.09-3.99), $P<0.001$ vs. summer). Regarding training phase, the highest probability of symptoms was during the Competition Phase which was from January to March (odds ratio (95\% CI): 1.68 (1.35-2.09), $P<0.001$ vs. General Preparation Phase), but training phase was no longer a significant risk factor when accounting for other variables. Season was also significantly associated with symptom duration, with symptoms reported during autumn $(b=0.024, P<0.01)$, winter $(b=0.043, P<0.001)$ and spring $(b=0.037, P<0.001)$ typically persisting for longer than those reported during the summer.

\section{Competition, air travel and altitude exposure}

International air travel was associated with unadjusted odds ratios of 4.53 (3.49-5.88) of reporting symptoms indicative of infection within the next day, 2.73 (2.25-3.31) of reporting symptoms within the next three days and 1.78 (1.52-2.06) of reporting symptoms within the next seven days (all $P<0.001$ ). When accounting for other independent variables, air travel was associated with adjusted odds ratios of 4.94 (3.74-6.53), $2.66(2.17-3.26)$ and 1.59 (1.361.85 ) of reporting symptoms within one, three and seven days, respectively (all $P<0.001$ ). Indeed, $35 \%$ of all recorded events were associated with an international flight during the preceding $72 \mathrm{~h}$. Of the 1769 flights recorded, 53\% were outbound and $47 \%$ were homebound, while $95 \%$ were continental and 5\% intercontinental. Homebound flights were more likely to be associated with the athlete subsequently reporting symptoms compared with outbound 
flights (14\% vs. $5 \%)$ as were intercontinental flights compared with continental flights (17\% vs. 9\%).Taking part in a competition was associated with unadjusted odds ratios of 2.74 (2.18-3.45) of an athlete reporting symptoms within the next day, 1.75 (1.57-1.95) of an athlete reporting symptoms within the next three days and 1.45 (1.35-1.55) of an athlete reporting symptoms within the next seven days (all $P<0.001$ ). When accounting for other independent variables, competition was associated with adjusted odds ratios of 2.93 (2.24$3.83), 1.78$ (1.56-2.03) and 1.51 (1.38-1.66) of an athlete reporting symptoms within one, three and seven days, respectively (all $P<0.001)$.

Exposure to altitude of $\geq 1,500$ masl was associated with an unadjusted odds ratio of 1.05 $(1.01-1.10)(P<0.05)$ of an athlete reporting symptoms within the next seven days, but was no longer significantly associated with symptom onset when accounting for other independent variables.

\section{Training}

The only training variable that was a significant risk factor for symptom onset in both unadjusted and adjusted models was Training Monotony. A 10\% increase in between-person Training Monotony was associated with an unadjusted odds ratio (95\% CI) of $0.86(0.79-0.93)$ $(P<0.001)$, and remained significant when accounting for other variables (odds ratio $(95 \%$ CI): $0.87(0.73-0.99), P<0.05)$. In unadjusted models, within-person increases in the volume of strength/power/sprint exercise was negatively associated with symptom onset (odds ratio (95\% CI): 0.83 (0.75-0.91) while within-person high-intensity endurance exercise was positively associated with symptom onset (odds ratio (95\% CI): 1.16 (1.03-1.31). However, both became non-significant when accounting for other independent variables. Betweenperson total training volume and Training Stress were both negatively associated with symptom onset in unadjusted models (odds ratio (95\% CI): $0.91(0.85-0.98)$ and $0.97(0.96-$ 
0.99), respectively) but became non-significant when adjusted for other independent variables. TRIMP was not a significant risk factor for symptom onset, nor was TRIMP during symptomatic episodes significantly associated with symptom duration.

The final adjusted multilevel model included the following variables, which were found to be significant predictors in the unadjusted models: season, training phase, competition, aircraft travel, altitude exposure, total training volume, volume of high-intensity training, volume of strength/power/sprint training and training monotony.

\section{DISCUSSION}

\section{Frequency and timing of symptoms of respiratory tract and gastrointestinal infection}

Our data indicate that elite cross-country skiers experience three to four episodes of selfreported respiratory and/or gastrointestinal infection per year, with symptoms typically lasting five days. Few other studies have examined infection rates in athletes for periods of more than a few weeks or months. However, Hellard et al. ${ }^{11}$ reported a similar frequency of infectious infection for elite swimmers who experienced, on average, four episodes of respiratory, gastrointestinal and/or urogenital infection per person-year. Hence, it appears that elite endurance athletes experience broadly similar infection rates, regardless of whether their competition season falls during the winter or summer months. Nor do these infection rates appear to deviate markedly from adults in the general population, who typically experience two to four respiratory tract infections per year ${ }^{78}$.

The Norwegian Institute for public health report that the average Norwegian experiences 2.4 respiratory tract infections per year ${ }^{19}$, compared to 3.0 amongst our group of athletes. Kuusi et al. ${ }^{20}$ found that the incidence of acute gastroenteritis in a sample of Norwegians was 1.2 per person-year in the period 1999-2000. This is substantially higher than the 0.4 episodes per 
year reported by these elite cross-country skiers. However, similar to the current study, Hansdotter et al. ${ }^{21}$ reported $0.3-0.4$ events of acute gastrointestinal illness per person-year in Sweden in the period 2008-2009. Determining precise incidence rates of both respiratory tract and gastrointestinal infections in the general population is challenging, since many may not report mild cold and influenza symptoms to the doctor. As such, we unfortunately do not have accurate epidemiological data on acute respiratory tract and gastrointestinal infections for the Norwegian general population specifically during the time period studied. However, it seems reasonable to conclude that, in general, elite cross-country skiers are no more prone to these types of infection than the general population. On the other hand, there does appear to be high inter-individual variability in infection susceptibility, even within a homogenous group of elite athletes. For the 37 athletes included in the current study, individual incidence rates ranged from 1-7 events per year, despite only minor differences in training load, travel and competition schedule or training environment.

Cross-country skiers report the highest frequency of symptoms during the winter months, similar to elite swimmers ${ }^{11}$ and mirroring seasonal patterns for both respiratory tract infections ${ }^{8}$ and norovirus infections ${ }^{22}$ in the general population. However, when adjusting for other variables, such as the number of competitions, spring was associated with the highest risk of symptoms. However, since these athletes typically train and compete on snow until mid-April, the months categorised as "spring" bear much resemblance to winter. Furthermore, it is during these months that vitamin D levels would be expected to be at their lowest, with recent research indicating that vitamin D deficiency is a predictor of infection in endurance athletes ${ }^{23}$. Since training phase was not a significant risk factor when adjusted for season, and since patterns of infection appear to be similar for summer and winter sport athletes, time of year appears to influence infection risk to a greater degree than which training phase the athlete is in. 


\section{Training- and competition-related risk factors}

The single biggest risk factor for infection was international air travel, making the athlete approximately five times more likely to report symptoms the subsequent day. This is in agreement with previous studies in non-athletes which have reported that $\sim 20 \%$ of individuals experience symptoms of respiratory infection within one week of commercial aircraft travel ${ }^{24}$ and that cabin staff are more predisposed to respiratory infections than the general population ${ }^{25}$. Schwellnus et al. ${ }^{26}$ found that athletes traveling to a foreign destination more than five time zones difference from their home country had a 2-3 fold increase in risk of illness. However, in contrast to the current study, homeward travel was not associated with an increased risk of symptoms. The majority of homebound flights included in the present analyses were following competition weekends, with athletes typically flying home the same day and often within a few hours of finishing the final competition. As such, it is possible to speculate that infection risk was further exacerbated because athletes were traveling home in an already somewhat immunocompromised state, since it is well-documented that acute bouts of strenuous and prolonged physical activity result in immune disturbances that persist for a number of hours ${ }^{27}$. Air travel is associated with a variety of stressors that may increase infection risk. These include: time-zone changes, sleep disruption, increased pathogen exposure due to crowded conditions in airports and on aircraft, mild hypoxia and drying of oral and nasal mucosa, as well as stressful events such as delays and lost luggage. Hence, although often unavoidable, athletes are advised to minimise air travel as much as possible, particularly immediately prior to important competitions and major championships. When competing in central Europe, driving between competition venues may be a preferable alternative to flying, provided the distance is feasible. Where this is not possible, flying out as early as possible prior to a major competition will reduce the likelihood of the athlete experiencing infection during the event itself, although this of course does not ameliorate the 
risk of an infection disrupting the training/tapering process. Following competitions abroad, delaying homeward travel until the subsequent day may be preferable to flying home on the same day.

In contrast to the findings of Foster ${ }^{18}$ neither TRIMP nor Training Stress were associated with increased incidence of self-reported infection at the between- or within-person level, when accounting for other risk factors. Although within-person changes in Training Monotony were not significantly associated with symptom onset, athletes with higher average Training Monotony reported somewhat fewer symptomatic episodes than those with lower Training Monotony. This finding suggests that a microcycle that avoids large fluctuations in total daily training load may be preferable to one that alternates between very hard and very easy days, at least in terms of reducing infection risk. This is an interesting finding and contrasts with current recommendations that athletes should add variety to limit training monotony ${ }^{27}$. However, rather than measuring only daily variation in TRIMP, a calculation that also accounts for differences in activity type (e.g. skiing vs. running) would give a more accurate indication of the true training monotony.

None of the other measured training variables were significantly associated with symptom onset or duration when accounting for other independent variables. This is in contrast to Hellard et al. ${ }^{11}$ who found that increases in high-load and resistance training augmented the risk of respiratory infection. In the current study, high-intensity endurance exercise was significantly associated with symptom onset only in the unadjusted models. This can likely be explained by the fact that high-intensity endurance exercise was a sum of all recorded time spent in Intensity Zones 3-5, including both interval training and competition. However, since competitions are associated with additional physiological and psychological stress above that typically encountered even during the most intense training sessions, competition was also treated as a separate binary variable (did the athlete compete? Yes/No). Since only 
competition remained significant in the adjusted model, it appears that some other factor than merely time spent at high-intensity contributes to the increase in infection susceptibility associated with competing. Whether this is related to greater psychological stress, greater physiological stress, environmental factors such as crowd exposure, or a combination of these, is not clear. Whatever the underlying mechanisms, the finding that taking part in competitions increases the risk of infection is in agreement with previous studies ${ }^{28}$, although Hellard et al. ${ }^{11}$ found that the risk of upper respiratory tract and pulmonary infections in swimmers was higher in the periods of intensive training than in both competition and postcompetition periods. Unlike swimmers, however, cross-country skiers perform their most intensive training during the summer and primarily compete during the winter months ${ }^{6}$ which may account for this discrepancy.

It is well known that ascent to high altitude alters both physiological and metabolic function, and can influence immune function ${ }^{13}$. However, it is not clear whether the moderate altitudes to which elite endurance athletes are typically exposed results in clinical changes in immunity and infection susceptibility. Tiollier et al. ${ }^{29}$ found no significant differences in mucosal immunity between elite cross-country skiers sleeping at 2500-3500 m above sea-level and training at $1200 \mathrm{~m}$ above sea-level for 18 days, compared with a control group who both lived and trained at $1200 \mathrm{~m}$ above sea-level. . In accordance with this, the current results suggest that training at moderate altitude does not significantly increase the risk of an athlete experiencing symptoms of respiratory or gastrointestinal infection when other factors, such as air travel to and from the altitude camp, are accounted for.

\section{Performance level, sex, age and family situation}

In the current study, the athletes of the highest performance level experienced fewer total days of symptoms compared to athletes of a lower performance level. Although it is not 
possible to determine cause and effect, this is in accordance with the findings of Hellard et al.

${ }^{11}$ that swimmers of a higher performance level had a lower risk of upper-respiratory tract infections, suggesting that a robust immune system capable of withstanding and recovering quickly from infection, even during periods of high physiological, psychological and environmental stress, may be a predictor of success in an otherwise homogenous group of elite athletes.

Although, in the general population, men appear to be somewhat more susceptible to viral and bacterial infections than women ${ }^{30}$ recent studies of athletes suggest a higher incidence of respiratory infections amongst females compared to males ${ }^{31-34}$. However, in the current study, sex was not significantly associated with either symptom incidence or duration. Nor was age a significant predictor of symptom incidence. Although previous studies have found that age influences the incidence rates of both acute gastrointestinal infection ${ }^{21}$ and respiratory tract infections ${ }^{8}$, the age range in the current study was comparatively narrow (18-34 years). Furthermore, since there were no significant differences between the recruit and senior team, number of years of athletic training, within the range studied, does not appear to influence the frequency of acute gastrointestinal and respiratory tract symptoms in this population.

There was no significant association between living in a household with young children and the incidence of symptoms indicative of upper respiratory or gastrointestinal infection. It should be noted, however, that only three of the athletes included in the study had children, and further research is therefore necessary to corroborate this.

\section{Limitations}

The current study design is associated with a number of limitations which should be acknowledged. Although a strength of the study is that it includes a very large amount of data for some of the world's best winter endurance athletes, a clear limitation is that both training 
and infection data was self-reported. Although elite cross-country skiers have previously been found to self-report their training accurately ${ }^{35}$, only $79 \%$ of 159 respiratory illnesses reported by athletes during the Sochi Olympic Games were due to infection ${ }^{34}$. Since not all symptoms in the current study were verified by a physician, it is likely that some of the events included in analyses were due to non-infectious causes. It is also possible that elite athletes are more/less apt to self-report illness than the general population. However, since the analyses are based only on comparisons within and between individuals from the same athlete group, a reporting bias is unlikely to be of major concern. It should also be noted that the current study does not include data on whether athletes suffered from asthma or allergies. This may have influenced the results, particularly since some symptoms of asthmatic and allergic reactions bear resemblance to those associated with upper-respiratory tract infection. Furthermore, Corne and colleagues ${ }^{36}$ found that individuals with asthma did not differ significantly in frequency, severity, or duration of upper-respiratory tract infections or symptoms associated with rhinovirus infection, but experienced more frequent lower-respiratory tract infections, with more severe and longer-lasting symptoms. Other factors not included in the current analyses may also have influenced symptom incidence, for example the presence of eating disorders, any habitual medication use or the presence of injuries. Munford \& Pugin ${ }^{37}$ found that the normal responses to injury can inhibit systemic inflammation and be immunosuppressive. As such, it is possible to speculate that athletes might be somewhat more susceptible to respiratory tract and/or gastrointestinal infections during periods of injury.

\section{CONCLUSION}

World-class cross-country skiers report 3-4 respiratory tract and gastrointestinal infections per year, with symptoms typically lasting 5 days. The highest incidence of such symptoms for these athletes occur during the winter months. However, world-leading athletes experience 
fewer symptomatic days per year compared to athletes of a lower performance level. Air travel and taking part in competitions both significantly increase the risk of symptoms. Since both are inherent components of international-level sport, future research exploring effective strategies to minimise infection risk associated with competition and air travel is warranted. In terms of reducing infection susceptibility, a microcycle that avoids large fluctuations in total daily training load may be preferable.

\section{What are the new findings?}

Elite cross-country skiers typically report 3-4 respiratory tract and gastrointestinal infections per year, with the highest incidence occurring during winter months. This is similar to annual patterns of infection reported for summer sport athletes.

Air travel and competition markedly increase the risk of symptoms.

$>$ Large day-to-day fluctuations in training load appear are associated with a small but significant increase in the frequency of symptoms.

$>$ World/Olympic medal-winning athletes report fewer symptomatic days per year than less successful athletes, but even within a homogenous athlete group there is large inter-individual variability in the frequency and duration of symptoms. Approximately $16 \%$ of athletes report $\geq 6$ respiratory tract and gastrointestinal infections per year and can be categorized as "illness prone".

\section{How might it impact clinical practice in the near future?}

Athletes, coaches and support staff should be aware of the times when athletes are particularly prone to infection (winter months and periods of competition and travel). Implementing effective hygiene procedures, promoting adequate recovery and optimising the nutritional status of athletes should be a particular priority at these times.

$>$ Athletes should avoid unnecessary air travel and excessive competition in the lead up to important events. It may be advantageous to delay homeward travel until the athlete is rested, rather than flying home immediately following competition.

$>$ Athletes are advised to avoid extreme day-to-day fluctuations in training load. 


\section{FOOTNOTES}

Contributors: ISS was involved in the study's design, data collection, analysis and interpretation, drafted and revised the manuscript, and approved the final version. IMT was involved in the data analysis and interpretation, critically revised the manuscript and approved the final version. ET developed the idea, critically revised the manuscript and approved the final version. RB was involved in the study's design, critically revised the manuscript and approved the final version. MG was involved in the study's design, interpretation, critically revised the manuscript and approved the final version.

Competing interests: None declared.

Ethical approval: Loughborough University.

Provenance and peer review: Not commissioned; externally peer reviewed. 


\section{REFERENCES}

1 Billat VL, Demarle A, Slawinski J, et al. Physical and training characteristics of top-class marathon runners. Med Sci Sports Exerc 2001;33(12):2089-97.

2 Billat V, Lepretre PM, Heugas AM, et al. Training and bioenergetic characteristics in elite male and female Kenyan runners. Med Sci Sports Exerc 2003;35(2):297-304.

3 Fiskerstrand A, Seiler KS. Training and performance characteristics among Norwegian International Rowers 1970-2001. Scand J Med Sci Sports 2004;14(5):303-10.

4 Neal CM, Hunter AM, Galloway SD. A 6-month analysis of training-intensity distribution and physiological adaptation in Ironman triathletes. J Sports Sci 2011;29(14):1515-23.

5 Zapico AG, Calderon FJ, Benito PJ, et al. Evolution of physiological and haematological parameters with training load in elite male road cyclists: a longitudinal study. J Sports Med Phys Fitness 2007;47(2):191-6.

6 Tonnessen E, Sylta O, Haugen TA, et al. The road to gold: training and peaking characteristics in the year prior to a gold medal endurance performance. PLoS One 2014;9(7):e101796.

7 Heikkinen T, Jarvinen A. The common cold. Lancet 2003;361(9351):51-9.

8 Monto AS. Epidemiology of viral respiratory infections. Am J Med 2002;112 Suppl 6A:4s$12 \mathrm{~s}$.

9 Gleeson M, Bishop N, Oliveira M, et al. Influence of training load on upper respiratory tract infection incidence and antigen-stimulated cytokine production. Scand J Med Sci Sports 2013;23(4):451-7.

10 Nieman DC. Is infection risk linked to exercise workload? Med Sci Sports Exerc 2000;32(7):S406-S11.

11 Hellard P, Avalos M, Guimaraes F, et al. Training-related risk of common illnesses in elite swimmers over a 4-yr period. Med Sci Sports Exerc 2015;47(4):698-707.

12 Malm C. Susceptibility to infections in elite athletes: the S-curve. Scand J Med Sci Sports 2006;16(1):4-6.

13 Mazzeo RS. Altitude, exercise and immune function. Exerc Immunol Rev 2005;11:6-16.

14 Wilder-Smith A, Mustafa FB, Peng CM, et al. Transient immune impairment after a simulated long-haul flight. Aviat Space Environ Med 2012;83(4):418-23.

15 Clow A, Hucklebridge F. The impact of psychological stress on immune function in the athletic population. Exerc Immunol Rev 2001;7:5-17. 
16 Matthews A, Pyne D, Saunders P, et al. A self-reported questionnaire for quantifying illness symptoms in elite athletes. Open Access J Sports Med 2010;1:15-22.

17 Banister EW, Calvert TW. Planning for future performance: implications for long term training. Can J Appl Sport Sci 1980;5(3):170-6

18 Foster C. Monitoring training in athletes with reference to overtraining syndrome. Med Sci Sports Exerc 1998; 30(7):1164-8.

19 Dudman SG, Ånestad G. Epidemiologi ved luftveisinfeksjoner (LVI). Nasjonalt Folkehelseinstitutt 2006.

20 Kuusi M, Aavitsland P, Gondrosen, B, et al. Incidence of gastroenteritis in Norway-a population-based survey. Epidemiol Infect 2003;131(01):591-597.

21 Hansdotter FI, Magnusson M, Kühlmann-Berenzon S, et al. The incidence of acute gastrointestinal illness in Sweden. Scand J Public Health 2015; 3(5):540-7.

22 Ånestad G, Vainio K, Hungnes O. Interference between outbreaks of epidemic viruses. Scand J Inf Dis 2007; 39: 653-654.

23 He CS, Handzlik M, Fraser WD, et al. Influence of vitamin D status on respiratory infection incidence and immune function during 4 months of winter training in endurance sport athletes. Exerc Immunol Rev 2013;19:86-101.

24 Zitter JN, Mazonson PD, Miller DP, et al. Aircraft cabin air recirculation and symptoms of the common cold. JAMA 2002;288(4):483-6.

25 Whelan EA, Lawson CC, Grajewski B, et al. Prevalence of respiratory symptoms among female flight attendants and teachers. Occup Environ Med 2003;60(12):929-34 .

26 Schwellnus MP, Derman WE, Jordaan E, et al. Elite athletes travelling to international destinations $>5$ time zone differences from their home country have a 2-3-fold increased risk of illness. Br J Sports Med 2012;46(11):816-21.

27 Walsh NP, Gleeson M, Pyne DB, et al. Position statement. Part two: Maintaining immune health. Exerc Immunol Rev 2011;17:64-103.

28 Nieman DC. Marathon training and immune function. Sports Med 2007;37(4-5):412-5.

29 Tiollier E, Schmitt L, Burnat P, et al. Living high-training low altitude training: effects on mucosal immunity. Eur J Appl Physiol 2005;94(3):298-304.

30 Klein SL. The effects of hormones on sex differences in infection: from genes to behavior. Neurosci Biobehav Rev 2000;24(6):627-38.

31 Engebretsen L, Steffen K, Alonso JM, et al. Sports injuries and illnesses during the Winter Olympic Games 2010. Br J Sports Med 2010;44(11):772-80. 
32 Engebretsen L, Soligard T, Steffen K, et al. Sports injuries and illnesses during the London Summer Olympic Games 2012. Br J Sports Med 2013;47(7):407-14.

33 He CS, Bishop NC, Handzlik MK, et al. Sex differences in upper respiratory symptoms prevalence and oral-respiratory mucosal immunity in endurance athletes. Exerc Immunol Rev 2014;20:8-22.

34 Soligard T, Steffen K, Palmer-Green D, et al. Sports injuries and illnesses in the Sochi 2014 Olympic Winter Games. Br J Sports Med 2015;49(7):441-7.

35 Sylta O, Tonnessen E, Seiler S. Do elite endurance athletes report their training accurately? Int J Sports Physiol Perform 2014;9(1):85-92.

36 Corne JM, Marshall C, Smith S et al. Frequency, severity, and duration of rhinovirus infections in asthmatic and non-asthmatic individuals: a longitudinal cohort study. The Lancet 2002;359(9309):831-834.

37 Munford RS, Pugin J. Normal responses to injury prevent systemic inflammation and can be immunosuppressive. Am J Respir Crit Care Med 2001;163(2):316-321. 